Research Paper

\title{
Adipose-Derived Stromal Cells Protect Intervertebral Disc Cells in Compression: Implications for Stem Cell Regenerative Disc Therapy
}

\author{
Zhen Sun ${ }^{*}$, Beier Luo ${ }^{2}$, Zhi-Heng Liu ${ }^{3}$, Dino Samartzis ${ }^{4}$, Zhongyang Liu ${ }^{1}$, Bo Gao ${ }^{1}$, Liangliang Huang ${ }^{1}$,
} Zhuo-Jing Luo ${ }^{1 凶}$

1. Department of Orthopedics, Xijing Hospital, Fourth Military Medical University, West Changle Road, Xi'an, 710032, China;

2. Department of Orthopedics, Changhai Hospital, The Second Military Medical University, Shanghai, 200433, China;

3. Department of Orthopedics, Air Force Hospital, Youyi Road 269, Xi'an, China;

4. Department of Orthopaedics and Traumatology, University of Hong Kong, Pokfulam, Hong Kong, SAR, China.

* Zhen Sun and Beier Luo contributed equally to this work.

$\bowtie$ Corresponding author: fmmusz@126.com.

() Ivyspring International Publisher. This is an open-access article distributed under the terms of the Creative Commons License (http://creativecommons.org/ licenses/by-nc-nd/3.0/). Reproduction is permitted for personal, noncommercial use, provided that the article is in whole, unmodified, and properly cited.

Received: 2014.09.21; Accepted: 2014.11.19; Published: 2015.01.01

\begin{abstract}
Introduction: Abnormal biomechanics plays a role in intervertebral disc degeneration. Adipose-derived stromal cells (ADSCs) have been implicated in disc integrity; however, their role in the setting of mechanical stimuli upon the disc's nucleus pulposus (NP) remains unknown. As such, the present study aimed to evaluate the influence of ADSCs upon NP cells in compressive load culture.

Methods: Human NP cells were cultured in compressive load at 3.0MPa for 48 hours with or without ADSCs co-culture (the ratio was 50:50). We used flow cytometry, live/dead staining and scanning electron microscopy (SEM) to evaluate cell death, and determined the expression of specific apoptotic pathways by characterizing the expression of activated caspases-3, -8 and -9 . We further used real-time (RT-) PCR and immunostaining to determine the expression of the extracellular matrix (ECM), mediators of matrix degradation (e.g. MMPs, TIMPs and ADAMTSs), pro-inflammatory factors and NP cell phenotype markers.

Results: ADSCs inhibited human NP cell apoptosis via suppression of activated caspase- 9 and caspase-3. Furthermore, ADSCs protected NP cells from the degradative effects of compressive load by significantly up-regulating the expression of ECM genes (SOX9, COL2A1 and ACAN), tissue inhibitors of metalloproteinases (TIMPs) genes (TIMP-1 and TIMP-2) and cytokeratin 8 (CK8) protein expression. Alternatively, ADSCs showed protective effect by inhibiting compressive load mediated increase of matrix metalloproteinases (MMPs; MMP-3 and MMP-13), disintegrin and metalloproteinase with thrombospondin motifs (ADAMTSs; ADAMTS-1 and 5), and pro-inflammatory factors (IL-1 beta, IL-6, TGF-betal and TNF-alpha).

Conclusions: Our study is the first in vitro study assessing the impact of ADSCs on NP cells in an un-physiological mechanical stimulation culture environment. Our study noted that ADSCs protect compressive load induced NP cell death and degradation by inhibition of activated caspase- 9 and -3 activity; regulating ECM and modulator genes, suppressing pro-inflammatory factors and preserving CK8. Consequently, the protective impact of ADSCs found in this study provides an essential understanding and expands our knowledge as to the utility of ADSCs therapy for intervertebral disc regeneration.
\end{abstract}

Key words: intervertebral disc; adipose-derived stromal cells; nucleus pulposus; compressive load. 


\section{Introduction}

Low back pain is the world's most disabling condition, affecting $80 \%$ of the population at one point in time. $[1,2]$ While the causes of low back pain are multifactorial, it has been generally associated with intervertebral disc degeneration (IDD). [3] Currently, available surgical and conservative treatment options are mostly aimed at relieving symptoms, rather than modifying the pathological processes.

Macroscopically, the intervertebral disc consists of three regions: nucleus pulposus (NP), annulus fibrosus (AF) and cartilaginous endplates. In the normal human disc, the central NP is made of extracellular matrix (ECM) interspersed by NP cells, which account for $1 \%$ of the tissue volume. In the progression of IDD, proteoglycan together with water content in the NP decreases. The gelatinous NP tissue becomes fibrous, further propogating IDD, and cracks and fissures may develop in the AF that may instigate the introduction of nerve fibers which may lead to the generation of pain. [4, 5] The etiology of IDD is attributed to numerous factors, such as age progression, genetics, lifestyle/environmental, and abnormal or altered biomechanics. [6, 7] In this aspect, numerous studies have noted that abnormal compressive load could lead to changes in disc cell synthesis and gene expression for collagens, proteoglycans and protease activation, as well as cell apoptosis. [8-10]

To combat the effects of IDD in hopes to repair/regenerate the disc and even alleviate pain, the application of stem cell therapy has made tremendous strides in the past decade in various animal models and for patient use. [11-13] In the adult, there are a large number of potential sources of stem cells, including adipose tissue, bone marrow, and other tissues. Notably, adipose-derived stromal cells (ADSCs) have been shown as a promising candidate with the convenience of availability and abundance. [14] While a great number of studies have focused on the differentiation of stem cells towards the NP cell phenotype in various conditions, some reports have suggested trophic influence of stem cells on degenerated NP cells. In particular, studies have demonstrated that marrow mesenchymal stem cells (MSCs) can upregulate the viability of NP cells in direct co-culture systems. $[15,16]$ In a study by Strassburg et al, [17] stem cells were shown to stimulate the endogenous NP cell population to regain a non-degenerate phenotype. Also, Miyamoto et al [18] found that matrix metalloproteinase-related genes in rabbit NP cells were suppressed by synovial mesenchymal stem cells. Caplan et al [19] noted that MSCs secrete a variety of cytokines and growth factors that exert beneficial functions for tissue repair. Consistent with these findings, our previous study has also showed that ADSCs could restore the functions of degenerated NP cells with up-regulated expression of COL2A1, ACAN, and COL6A2 following direct co-culture of these two types of cells. [20]

Although ADSCs hold promise, their "impact" on NP cells in compressive load culture remains unknown. Since biomechanics is essential component to the integrity of the disc, an abnormal load could lead to apoptosis of NP cells and degeneration. However, whether ADSCs restore the detrimental influence of the mechanical factors upon the disc remains unanswered. In fact, mechanical stimuli, such as abnormal compressive load, are important factors in actual in vivo stem cell transplantation as most degenerated discs may be in un-physiological biomechanical environment. To date, there have been no studies addressing the impact of ADSCs on NP cells with regard to compressive load cultures. As such the present study addressed the influence of ADSCs upon NP cells in compressive load culture to further understand their role, in particular their utility for IDD regenerative therapies

\section{Materials and Methods}

\section{Tissue Collection}

The current study was approved by the Institutional Ethics Review Board of Xijing Hospital. Human NP samples and magnetic resonance imaging (MRI) data were obtained as described previously. [7] Briefly, written informed consents were collected from each patient. NP tissues were obtained from patients with idiopathic scoliosis undergoing anterior discectomy and fusion $(n=8$; average age 19.6 (range 16-26) years). The lipoaspirated fat tissues were obtained from volunteers $(n=8$; average age 31.8 , range 24-39 years). By analyzing the MRI data, we classified the discs as Grade II according to Pfirrmann's grading system.

\section{Human NP Cell Isolation and Cultures}

Human NP tissues were obtained within 2 hours after surgery. NP tissues were identified and separated by a stereotaxic microscope. The NP tissues were then washed with phosphate buffered saline (PBS) and digested for 40 minutes in $0.2 \%$ pronase (Gibco BRL, Carlsbad, CA, USA). Following being washed, the tissues were incubated in $0.25 \%$ type II collagenase (Gibco BRL, Carlsbad, CA, USA) at $37^{\circ} \mathrm{C}$ under gentle agitation for 4 hours. Then, the tissue debris was detached by a $45-\mu \mathrm{m}$ pore-size nylon mesh. Following centrifuged at $200 \mathrm{~g}$ for $8 \mathrm{~min}$, cells were seeded in culture flasks with DMEM/F12-based medium (containing 10\% FBS, 1\% P/S). The culture flasks were then placed in incubator with $20 \%$ oxygen and $5 \% \mathrm{CO}_{2}$ at $37^{\circ} \mathrm{C}$. 


\section{Human ADSCs isolation and verification}

Fat samples were washed and minced in a sterile petridish with PBS to prevent dehydration. Following digested in $1 \mathrm{mg} / \mathrm{ml}$ type II collagenase (Sigma, Saint Louis, USA) at $37^{\circ} \mathrm{C}$ under gentle agitation, the cells were passed through a $70 \mu \mathrm{m}$ pore-size sterile nylon mesh filter (Falcon, Franklin Lakes, USA). Then, the cells were harvested after centrifugation at $200 \mathrm{~g}$ for 8 minutes. To remove remaining tissue debris, the pellet was resuspended and filtered through a $40 \mu \mathrm{m}$ cell strainer. Cells were counted and seeded in culture flasks. The culture medium was changed twice a week. Cells were trypsinized, centrifuged at $500 \mathrm{~g}$ for 5 minutes and re-seeded when confluent.

We performed flow cytometry analysis $\mathrm{w}$ to verify the cultured ADSCs. In brief, the cultured cells were washed and incubated in blocking buffer for 30 minutes at $4{ }^{\circ} \mathrm{C}$. After being washed, the cells were then incubated for 30 minutes at $4{ }^{\circ} \mathrm{C}$ in dark with the fluorescein isothiocyanate (FITC)-conjugated antibodies or thephycoerythrin (PE)-conjugated antibodies as follows: c-kit/FITC, CD9/FITC, CD31/FITC, CD34/FITC, CD90/FITC, CD271/FITC, MAP-2/FITC,VEGF/FITC, KDR/PE, CD29/PE, CD45/PE (BD Biosciences, NJ, USA). To fix the cells, $1 \%$ paraformaldehyde was used. Isotype-identical antibodies (IgG) were used as controls. Cell viability of each group was greater than $96.0 \%$. Sample assessment was performed in three times.

\section{Indirect co-cultures of NP cells and ADSCs}

The indirect co-culture system was established with $0.4 \mu \mathrm{m}$ pore-size Transwell inserts placed in culture dishes. Passage $=1$ NP cells and Passage $=3$ ADSCs were used. ADSCs were plated into Transwell inserts $\left(5 \times 10^{6}\right.$ per well $)$ and NP cells were seeded in culture dishes $\left(5 \times 10^{6}\right.$ per well) with $10 \%$ DMEM-F12 culture medium. The ratio of the co-culture was 50/50. Eight NP cell samples and eight AD-MSCs samples were used via random pairing for the co-cultures.

\section{Compressive load culture}

The co-culture system was subjected to a compressive load environment, which was consisted of compression culture chamber and gas cylinder (Taikang Bio-Technology, Xi'an, China). To provide compressive stress, the culture chamber was linked with a high pressure gas cylinder. The samples were then subjected to controllable compressive stress at 3.0 MPa for 48 hours. [21-23] The culture chamber works with compressed gas from the cylinder to the culture dishes, leading to compression of fluid media to the NP cells under controlled pressure. For the control group, NP cells were cultured without ADSCs at the same condition.

\section{Experimental assays}

\section{Flow cytometry of cell apoptosis}

To address apoptosis of NP cells, Flow cytometry was performed with Annexin V-FITC/PI (BD Biosciences, San Diego, CA, USA) staining upon the treated cells. Briefly,, $1 \times 10^{6}$ cells were re-suspended in binding buffer after washed with PBS. Then the cells were incubated in Annexin V-FITC and PI at room temperature for 15 minutes. The samples were analyzed. Each experiment was performed in triplicate.

\section{Activated caspase $-8,-9$ and -3 assays}

We examined the expression of activated caspases- $8,-9$ and -3 by Caspase-Glo assay (Promega). In brief, caspase enzyme specific to luminogenic-substrate is cleaved by active caspases in the cell lysate releasing a substrate for luciferase. According to the experimental design, $100 \mathrm{ul}$ caspase was added to NP cell medium. Prior to utilization, $60 \mathrm{uM}$ proteosome inhibitor $\mathrm{MH}-132$ was added to the caspase reagent. After incubated at room temperature for 75 minutes, luminescence was detected with Perkin Elmer Victor3 Multilabel coulter. Background controls were used by luminescence from dishes that containing caspase reagent and media without cells. Each experiment was performed in triplicate.

\section{Live/Dead assay}

For assessing NP cells survival and proliferation, the Live/Dead assay was performed. The analysis employed two color fluorescent dyes (Live/Dead Cell Staining Kit, BioVision USA): LiveDye that produces green fluorescen for live cells and dead cells and propidium iodide (PI) that produces an intense red fluorescent for dead cells. In brief, the NP cells were incubated with $1 \mathrm{ml}$ of fresh serum-free DMEM/F12 containing $5 \mathrm{mM}$ of LiveDye and $5 \mathrm{mM}$ of PI for $3 \mathrm{~h}$ at room temperature. The NP cells were then washed by PBS to remove unbounded reaction products. After that, the samples were viewed by a microscope (FV-1000, Olympus, Japan) equipped for fluorescent detection. For image capturing, an Optronics digital CCD camera was used. Analysis was performed by A FV10-ASW 3.1 Viewer (Olympus, Japan).

\section{Scanning electron microscopy}

The adhesion of NP cells in each group was measured by scanning electron microscopy (SEM). Briefly, 4\% paraformaldehyde was used to fixe NP cells at room temperature for $30 \mathrm{~min}$. The samples were washed three times with distilled water and dehydrated with serial ethanol solutions. Following dried under vacuum at room temperature, samples were sputter-coated with gold, and then subjected to 
scanning electron microscopy (Hitachi S-3400N, Japan) at an accelerating voltage of $5 \mathrm{kV}$.

\section{Quantitative Real-Time PCR (qRT-PCR) Analysis}

We homogenized the NP cells in Trizol Reagent (SigmaAldrich, US) and used High-Capacity cDNA Archive Kit (ABI, Foster City, CA) to perform reverse transcription, then followed the instruction to perform RT-PCR. The sequences of primers are shown in

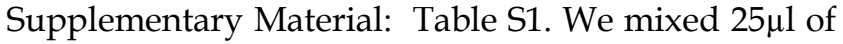
sample cDNA, $2.5 \mu \mathrm{l}$ of 10XPCR buffer, $2.0 \mu \mathrm{l}$ of

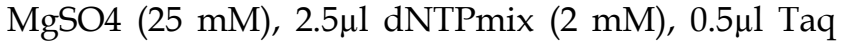
DNA Polymerase $(2 \mathrm{U} / \mu \mathrm{l})$, and $15.8 \mathrm{ml}$ deionized $\mathrm{H} 2 \mathrm{O}$ in the $\mathrm{PCR}$ reaction process.then the mixture was heated to $95^{\circ} \mathrm{C}$ for $2.5 \mathrm{~min}$ and then amplified for 40 cycles as follows: $95^{\circ} \mathrm{C}$ for $30 \mathrm{~s}$ (denaturation), $55^{\circ} \mathrm{C}$ for $30 \mathrm{~s}$ (annealing), and $65^{\circ} \mathrm{C}$ for $10 \mathrm{~s}$ (extension).

\section{Immunofluorescent staining}

Adhered NP cells were fixed using 2.5\% paraformaldehyde for $15 \mathrm{~min}$ at room temperature then treated with $0.2 \%$ Triton $\mathrm{X}-100$ for 1 minute. After that, cells were blocked in $1 \%$ bovine serum albumin PBS and e incubated in rabbit polyclonal anti-collagen II antibody, rabbit monoclonal antibody to (cytokeratin 8) CK8 (Abcam, Cambridge, USA) in 12h in $4^{\circ} \mathrm{C}$. afterwards, The samples were washed and incu-

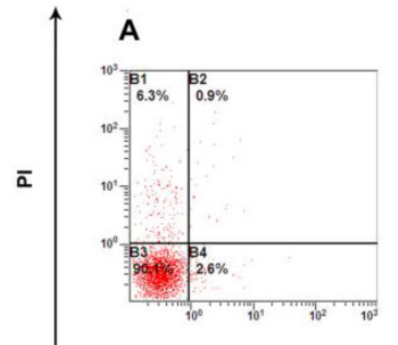

B

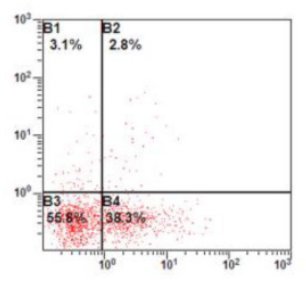

Annexin V-FITC
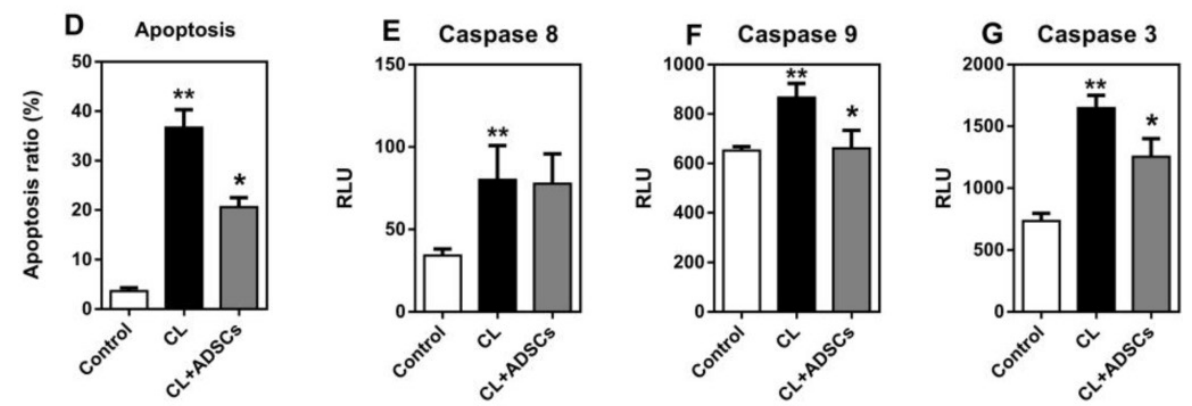

Figure 1: Apoptosis and activated caspases analysis in NP cells. (A-D) Representative sample of flow cytometry analysis of NP cell death (Annexin V ( X axis) and PI (Y axis) staining). All experiments were performed in three times. (A) NP cells treated without compressive load or ADSCs, (B) NP cells treatment with CL(compressive load), (C) NP cells treated with CL+ADSCs. (D) Summary of flow cytometry NP cell death assays (triplicate experiments as depicted in Figure 1 (A-C) above). Treatment of compressive load at 3.0MPa for $48 \mathrm{~h}$ increased the percentage of apoptosis cells $(* * p<0.01)$. The use of ADSCs significantly down-regulated the percentage of apoptosis cells $(* p<0.05)$. Data was performed in triplicate. To further clarify the mechanisms underlying ADSCs-mediated anti-apoptotic effects, we measured activated caspase activity of the NP cells. (E) No significant difference was detected in the expression of activated caspase-8 in among the groups $(p>0.05)$. $(F, G)$ ADSCs significantly suppressed the expression of activated caspase- 9 and caspase- 3 activity $\left({ }^{*}<0.05\right)$. Abbreviations: ADSCs (adipose-derived stromal cells), CL (compressive load), NP (nucleus pulposus), PI (Propridium lodide). bated with Alexa 488-conjugated goat anti-rabbit secondary antibodies (Molecular Probes, Eugene, OR, USA) for 30 minutes in the dark at room temperature.Dapi(4'-6-diamid-ino-2-phenylindole) was used as DNA counterstain. Slides were visualized using a Leica microscope (Leica, Wetzlar, Germany).

\section{Statistical analysis}

The SPSS statistical package (SPSS, Chicago, IL, USA) for statistical analysis was used. We used Student's t-test in the analysis of two-group parameters. ANOVA test was used in comparisons of multiple group data. A $p$ value $<0.05$ was considered significant.

\section{Results}

\section{ADSCs identification} more than $95 \%$ of the total cell population, and CD9 displayed nearly $85 \%$. In contrast, only a small proportion of cells were detected with negative ADSCs markers (see Supplementary Material: Table S2).

\section{Compressive load mediated apoptosis in hu- man NP cells can be rescued by ADSCs}

Mechanical stimuli associated with weight-bearing and loading of IVD are thought to be important regulators of NP cell metabolism. In the current study, we induced apoptosis of monolayer cultured human NP cells by un-physiological compressive load condition and measured cell death by flow cytometry. The time point was chosen after optimization. Nucleus pulposus cells labelled by $\mathrm{AV}$ and PI were quantified using flow cytometry allowing discrimination among viable cells (Q3: AV-PI-), early apoptotic cells (Q4: AV+PI-) and necrotic cells (Q2: AV-PI+). Nucleus pulposus cells were harvested and the percentage of early apoptotic and necrotic cells was determined using flow cytometry. As shown in Figure 1A-D, treatment with ADSCs resulted in a significant reduction in apoptotic (AV+PI-) cells following compressive load 
culture $(\mathrm{p}<0.01)$. No significant difference was observed in the percentage of necrotic cells (AV-PI+) when ADSCs were used in compressive load culture. To further clarify the mechanisms underlying ADSCs-mediated anti-apoptotic effects, we measured activated caspase activity of the NP cells. As shown in Figure 1E, there were no differences in the expression of activated caspase- 8 in any of the treatment groups $(p>0.05)$. However, ADSCs significantly suppressed the expression of activated caspase- 9 and caspase- 3 activity $(\mathrm{p}<0.05)$ (Figure 1F-G).

Meanwhile, the effect of ADSCs on survival of the NP cells was further examined by a Live/Dead staining method. The representative images of Live/Dead staining from each group are shown in Figure 2A. The percentage of live NP cells was significantly up-regulated by ADSCs after compressive load culture compared to that without ADSCs $(p<0.01)$ in Figure 2B. In addition, the morphological appearances of NP cells in each group were evaluated by SEM. As shown in Figure 2C-E, NP cells in each group attached, spreaded, and started to divide. When cultured followed compressive load culture, NP cells without ADSCs were shrinking with broken membranes and particulates at 48 hours (Figure 2D). In contrast, most of NP cells in compressive load group with ADSCs extended bipolar or multipolar processes at 48 hours after exposure to compressive load, which were similar to that in control group (Figure 2E). The SEM results were consistent with the apoptosis assay results.

\section{ADSCs in compressive load culture prevented ECM decrease in NP cells}

The gene expression of SOX9, COL2A1, ACAN, and COL6A2 was significantly decreased by the un-physiological compressive load culture $(\mathrm{p}<0.01)$. The utilization of ADSCs in cultures with compressive load had a significant effect upon ECM proteins in gene and protein levels,. As shown in Figure 3A, the expression of Sox9, a transcription factor known to facilitate COL2A1 expression, was increased by ADSCs following compressive load culture $(\mathrm{p}<0.01)$. Also, ADSCs could up-regulate COL2A1 and ACAN gene expression and demonstrated a markedly increased difference (Figure 3B and C) $(\mathrm{p}<0.01)$. However, the expression of COL6A2 was increased by ADSCs, but did not reach statistical significance (Figure 3D) ( $p>0.05)$. Additionally, the expression of collagen 2 was confirmed by immunostaining, as shown in Figure 3E. Quantification analysis showed the percentage of collagen 2 positive staining cells was decreased by compressive load at 3.0MPa for 48 hours and the use of ADSCs significantly up-regulated collagen 2 expression $(\mathrm{p}<0.05)$ (Figure 3F).
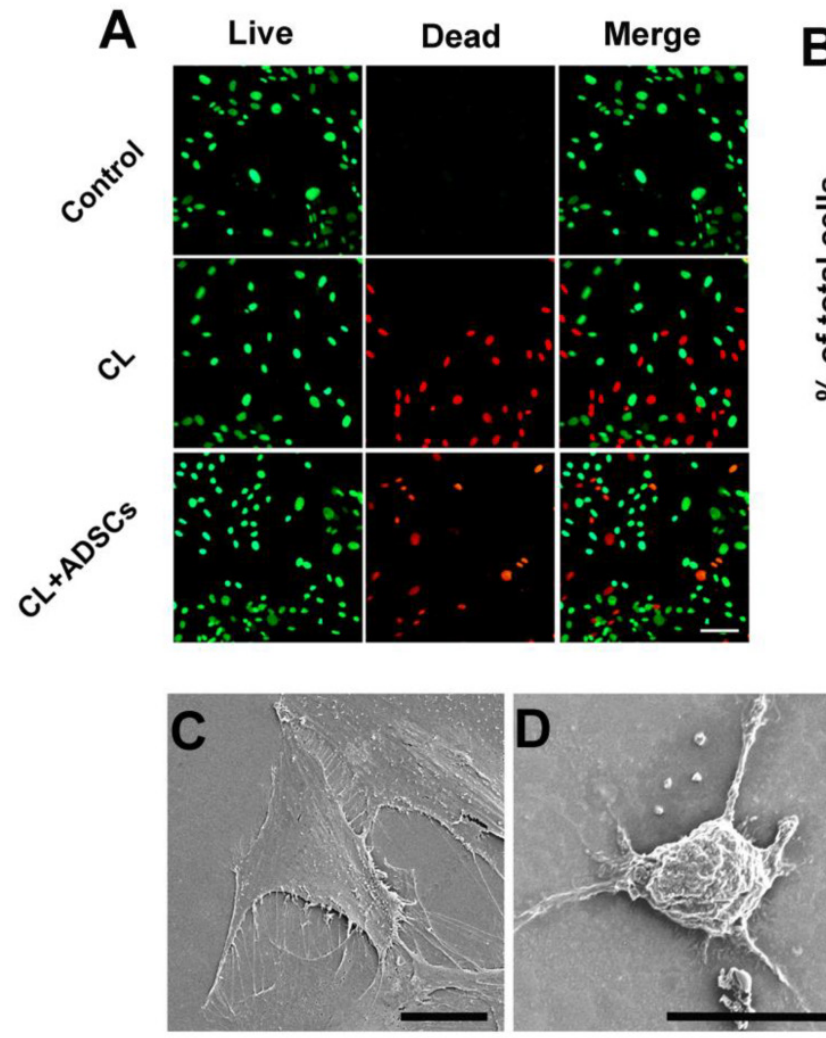

Control

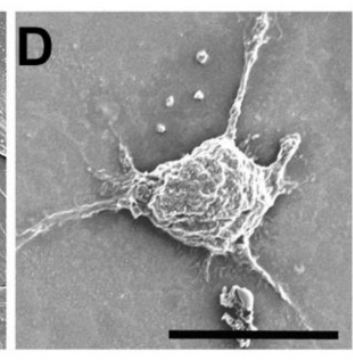

CL
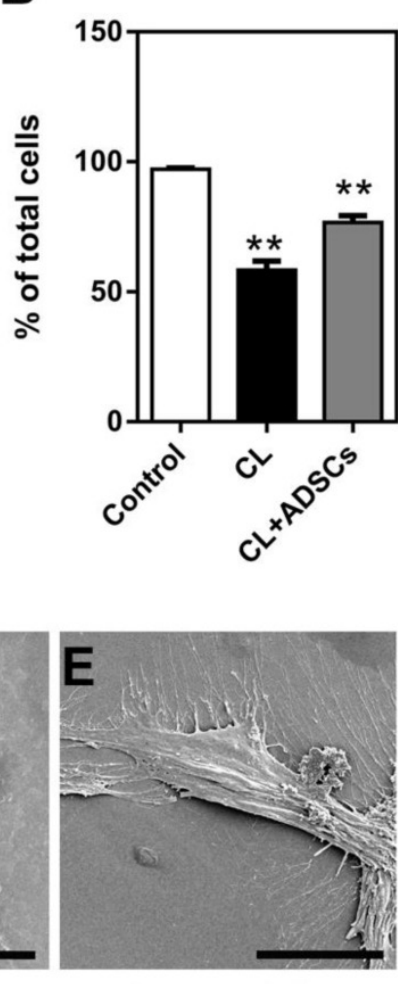

CL+ADSCs
Figure 2: Live/Dead staining and SEM photomicrographs of cultured NP cells at 3.0MPa for $48 \mathrm{~h}$. (A) The representative images of Live/Dead staining of cultured NP cells. Bar $=100 \mu \mathrm{m}$. (B) The percentages of living NP cells for each group are shown. Treatment of compressive load at 3.0MPa decreased the percentage of living cells at $48 \mathrm{~h}(* * \mathrm{p}<0.01)$. The differences between $C L$ and $C L+A D S C s$ in terms of living cells are statistically significant $\left({ }^{*} p<0.05\right)$. Data was performed in triplicate. (C) SEM photomicrographs showed NP cells in each group attached, spreaded, and started to divide. When cultured following compressive load culture at 3.0MPa for $48 \mathrm{~h}$, NP cells without ADSCs were shrinking with broken membranes and many particulates. In contrast, the NP cells in compressive load group with ADSCs extended bipolar or multipolar processes at $48 \mathrm{~h}$ after exposure to 3.0MPa compressive load, which were similar to that in control group. Bar $=20 \mu \mathrm{m}$. Abbreviations: ADSCs (adipose-derived stromal cells), CL (compressive load), NP (nucleus pulposus), SEM (scanning electron microscopy). 
A

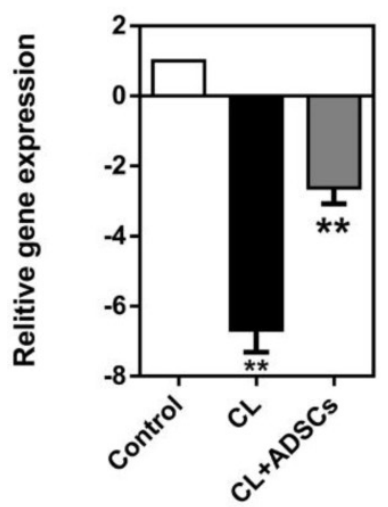

C Aggrecan

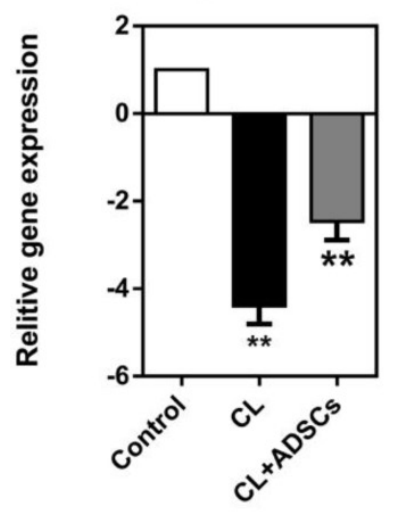

B Collagen 2

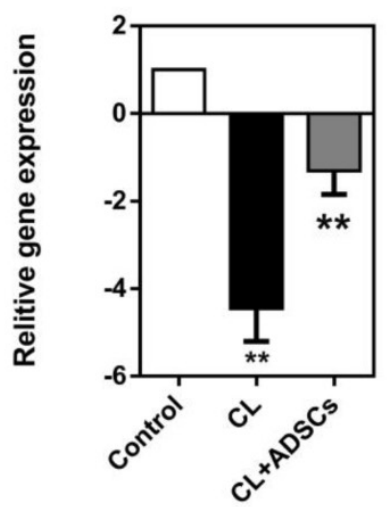

D Collagen 6

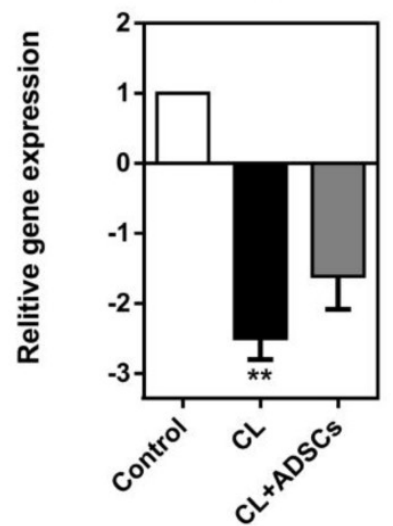

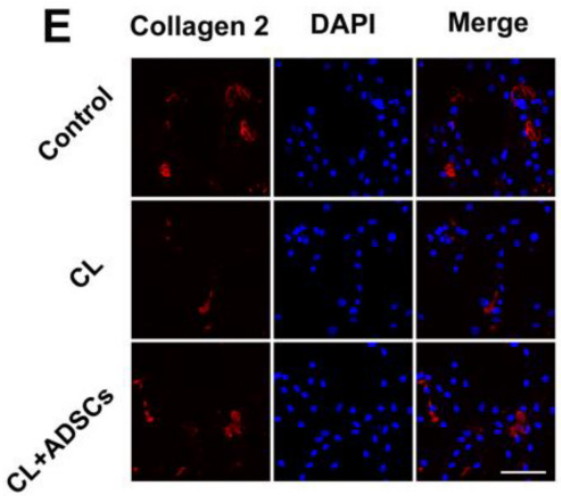

F

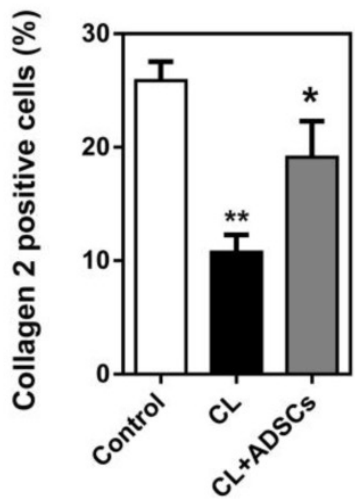

Figure 3: Expression of SOX9, COL2A1, ACAN, and COL6A2 in NP cells. Quantitative mRNA gene expression analysis was used to evaluate the expression of a panel of chondrogenic (SOX9, COL2A1, ACAN, and COL6A2) marker genes. Additionally, collagen 2 staining was performed in cultured NP cells. (A-C) The gene expression of SOX9, COL2A1 and ACAN in NP cells was decreased by compressive load culture at 3.0MPa for 48h in CL group (**p<0.01). The use of ADSCs significantly up-regulated these genes expression in the CL+ADSCs group $\left({ }^{* *} \mathrm{p}<0.01\right)(\mathrm{D}) \mathrm{COL6A1}$ gene expression in NP cells was decreased by compressive load culture at $3.0 \mathrm{MPa}$ for $48 \mathrm{~h}$ in $\mathrm{CL}$ group. The use of ADSCs insignificantly up-regulate SOX9 gene expression in the CL+ADSCs group ( $>0.05)$. (E-F) The representative images of collagen 2 staining in NP cells. Quantification analysis showed the percentage of collagen 2 positive staining cells was decreased by compressive load at $3.0 \mathrm{MPa}$ for $48 \mathrm{~h}$ in $\mathrm{CL}$ group (** $<0.01$ ). The use of $A D S C s$ significantly up-regulated collagen 2 expression in the CL+ADSCs group ( $\left.{ }^{*} \mathrm{p}<0.05\right)$. Abbreviations: ADSCs (adipose-derived stromal cells), CL(compressive load), NP (nucleus pulposus).

\section{Impact of ADSCs on MMPs, TIMPs and ADAMTSs in NP cell and modulators synthesis}

We examined the expression of these cytokines in the current study. As shown in Figure 4, NP cells exhibited a significantly increased expression of MMP-3 and MMP-13 in compressive load culture $(p<0.01)$. The use of ADSCs strongly reduced the expression of MMP-3 and MMP-13(p<0.05). Moreover, TIMP-1 and TIMP-2 showed an up-regulation in NP cells after co-cultured with ADSCs following compressive load culture $(p<0.05)$. Additionally, the NP cells demonstrated an up-regulated expression of ADAMTS-1, 4, and 5 following compressive load culture $(p<0.01)$. ADSCs were shown to inhibit ADAMTS- 1 and 5 expression following compressive load compared with culture without ADSCs $(p<0.05)$.

\section{ADSCs led to pro-inflammatory factors in de- crease in compressive load cultured NP cells}

A variety of inflammatory mediators have been implicated in IVD degeneration. In the current study, we detected interleukin-1 $\beta$ (IL-1 $\beta$ ), interleukin-6 (IL-6), transforming growth factor $\beta 1$ (TGF- $\beta 1$ ) and tumor necrosis factor alpha (TNF-a). As shown in Figure 5, we found that the expression of IL-1 $\beta$, IL-6, TGF- $\beta 1$ and TNF- $\alpha$ was significantly increased by compressive load culture in NP cells $(p<0.01)$, and that ADSCs significantly suppressed the expression of IL-1 $\beta$, TGF- $\beta 1$, TNF- $\alpha(p<0.01)$ and IL-6 $(p<0.05)$ in compressive culture.

\section{NP cell phenotype detection following com- pressive load culture}

It is suggested that NP cells demonstrated phenotype degradation with some markers down-regulated. Here, we measured the gene ex- 
pression of FOX1 (forkhead box F1), PAX1 (paired box 1), CA12 (carbonic anhydrase XII) and CK8, which was proved to be specifically expressed in NP cells compared with AF cells and chondrocytes. We found that the gene expression of FOXF1, PAX1, CA12 and CK8 was decreased by compressive load. Although their expression was up-regulated by ADSCs, there was no significant difference between the two groups with or without ADSCs (Figure 6A-D), ( $>>0.05)$. Interestingly, we found that CK8 was down-regulated by compressive load culture in protein level. The use of ADSCs led to an increase in the expression of CK8 (Figure 6E-G).

\section{Discussion}

Adipose-derived stromal cells have been reported to be a promising candidate in disc regeneration treatment options. Accumulating evidence has shown that stem cell injection into the NP tissue is an effective IDD biological therapy. [11, 24-27] Practically, patients with degenerative disc disease might be treated with the ADSCs injection treatment before all NP cells are exhausted. Therefore, while the differentiation of ADSCs is an important issue, the impact of ADSCs on the remaining degenerated NP cells needs to be clarified in order to get a comprehensive understanding of stem cells treatment for IDD. Our previous study demonstrated that direct co-culture of human ADSCs and NP cells resulted in increased matrix formation in degenerated NP cells. [20] Additionally, we have also shown that ADAMTSs and CK8 expression was affected by compressive load cultures in human NP cells. [28, 29] However, the question remains open on the impact of ADSCs' upon NP cells in abnormal compressive load, which might be a similar scenario with the actual IVD biomechanical environment. In this study, we found that ADSCs protect NP cells from apoptosis and degradation under a compressive load culture environment, which might shed light on implications in stem cell therapy for intervertebral disc regeneration.

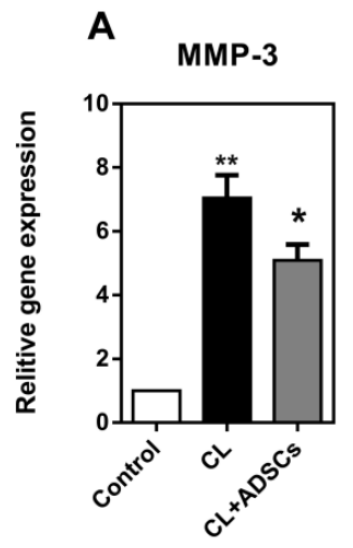

B

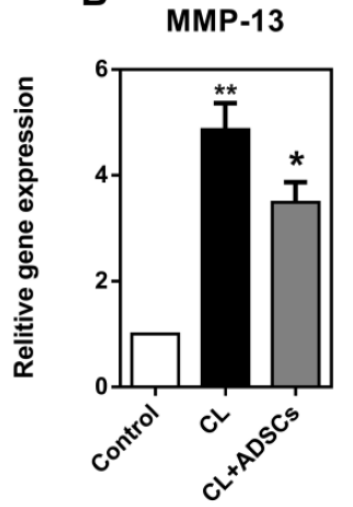

C

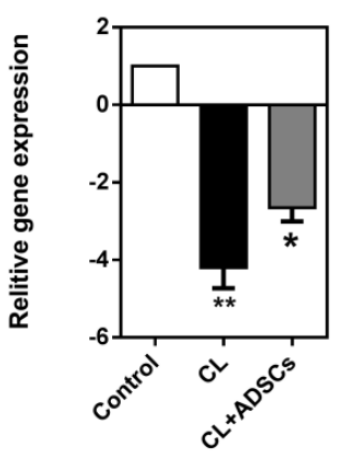

D

TIMP-2

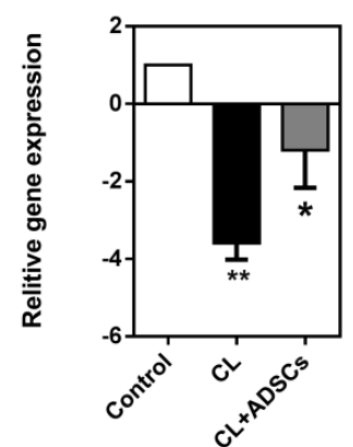

E

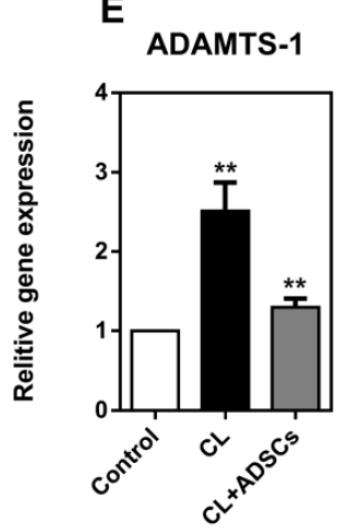

$\mathbf{F}$

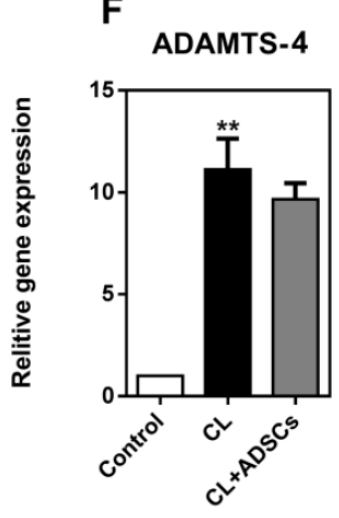

G

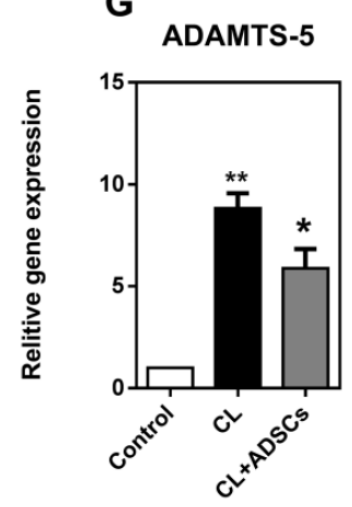

Figure 4: Relative gene expression for MMP-3, MMP-13, TIMP-1, TIMP-2, ADAMTS-1, 4, and 5 (matrix remodeling genes) expressed by NP cells (real-time PCR (qRT-PCR). Reading from left to right on each graph the white bar reflects NP cells treated without compressive load or ADSCs, the black bar is treatment with $\mathrm{CL}$ (compressive load), and the grey bar NP cells treated with CL+ADSCs. (A-B) NP cells exhibited an increased expression of MMP-3 and MMP-13 in compressive load culture at 3.0MPa for $48 \mathrm{~h}(* * \mathrm{p}<0.01)$. The use of ADSCs strongly reduced the expression of MMP-3 and MMP-13 (*p<0.05). (C-D) TIMP-1 and TIMP-2 showed an up-regulation in NP cells after co-cultured with ADSCs following compressive load culture at 3.0MPa for $48 \mathrm{~h}\left({ }^{*} \mathrm{p}<0.05\right)$. (E-G) The NP cells demonstrated an up-regulated expression of ADAMTS-1, 4 , and 5 following compressive load culture at 3.0MPa for $48 \mathrm{~h}\left({ }^{* *} \mathrm{p}<0.01\right)$. ADSCs can inhibit ADAMT-1 and 5 expression significantly following compressive load compared with culture without ADSCs ( ${ }^{*}<0.05$, **p<0.01). Abbreviations: ADSCs (adipose-derived stromal cells), CL(compressive load), NP (nucleus pulposus), MMPs (matrix metalloproteinases), ADAMTSs (A disintegrin and metalloproteinase with thrombospondin motifs), TIMPs (tissue inhibitor of matrix metalloproteinases), qRT-PCR (quantitative real-time polymerase chain reaction). 

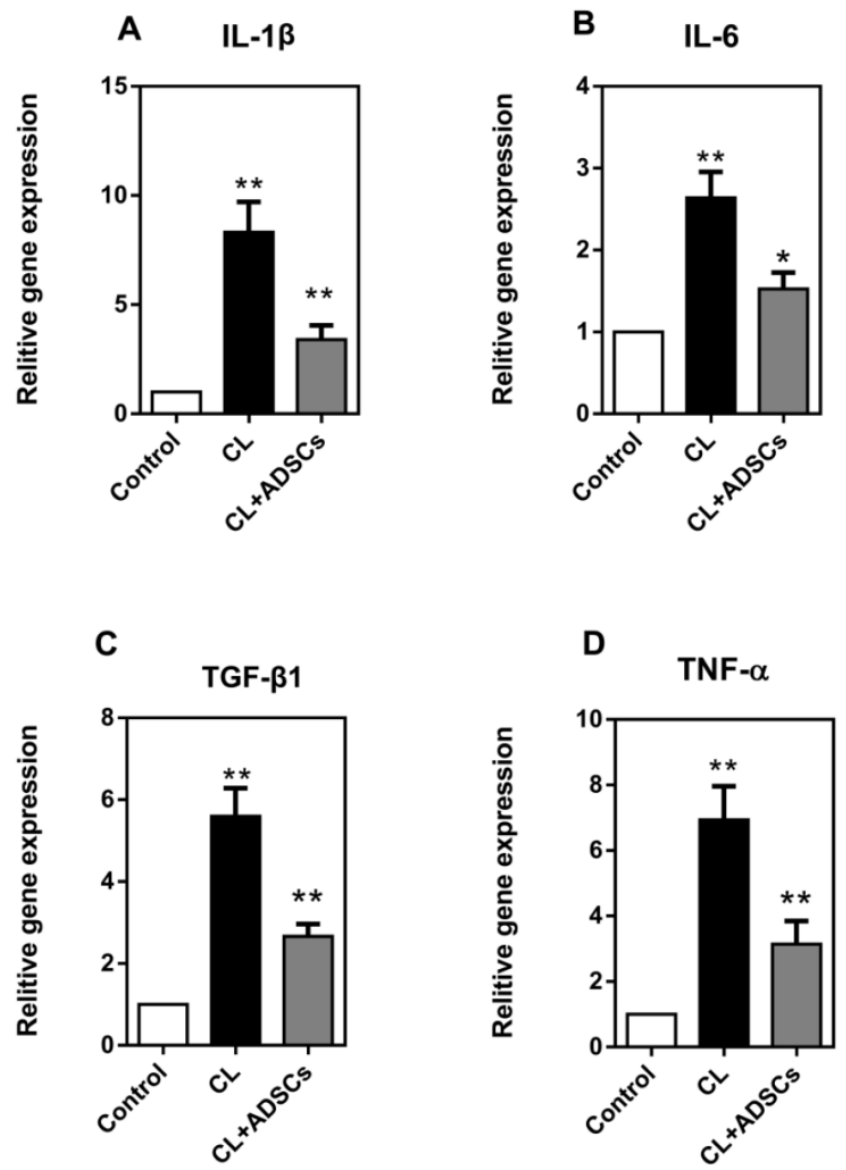

Figure 5: NP cell expression of pro-inflammatory factors (qRT-PCR). (A) Expression of IL-1 $\beta$ gene by NP cells treated with compressive load culture at 3.0MPa for $48 \mathrm{~h}$ induce a dramatic increase in the expression of the gene encoding $\mathrm{IL}-1 \beta(* * \mathrm{*}<0.01)$; however, the use of ADSCs results in a dramatic reduction of NP cell expression of IL-1 $(* * p<0.01)$. (B) NP cells treated with compressive load culture at $3.0 \mathrm{MPa}$ for $48 \mathrm{~h}$ induce a dramatic increase in the expression of the gene encoding IL-6 $(* * p<0.01)$; the use of ADSCs results in a reduction of NP cell expression of IL-6 $\left({ }^{*} \mathrm{p}<0.05\right)$ (C) NP cells treated with compressive load culture at 3.0MPa for $48 \mathrm{~h}$ induce a dramatic increase in the expression of the gene encoding TGF- $\beta 1$ (** $p<0.01$ ); however, the use of ADSCs results in a strongly reduction of NP cell expression of TGF- $\beta 1$ (** $\left.*^{*}<0.01\right)$. (D) Expression of TNF- $\alpha$ gene by NP cells treated with compressive load culture at 3.0MPa for $48 \mathrm{~h}$ induce a dramatic increase in the expression of the gene encoding TNF- $\alpha\left({ }^{* *} p<0.01\right)$; however, the use of ADSCs results in a dramatic reduction of NP cell expression of TNF- $\alpha\left({ }^{* *} p<0.01\right)$. Abbreviations: ADSCs (adipose-derived stromal cells), CL (compressive load), NP (nucleus pulposus), qRT-PCR (quantitative real-time polymerase chain reaction).

To our knowledge, this is the first in vitro study investigating the impact of ADSCs on NP cells in an un-physiological mechanical stimulation culture environment. Progressive IDD is associated with cell death of NP cells, which play an important role in functional ECM synthesis, cytokines production and the maintenance of relevant enzymes' activities. The decrease of NP cell population from cell death is found in most IDD pathology. [30] Caspase-9 and -3 are involved in downstream of the intrinsic (mitochondrial) apoptotic pathway while caspase- 8 is a key agent in the upstream of the extrinsic apoptotic pathway, which is linked with the Fas/FasL receptor. Accumulating evidence has shown that abnormal compressive load can lead to apoptosis in NP cells
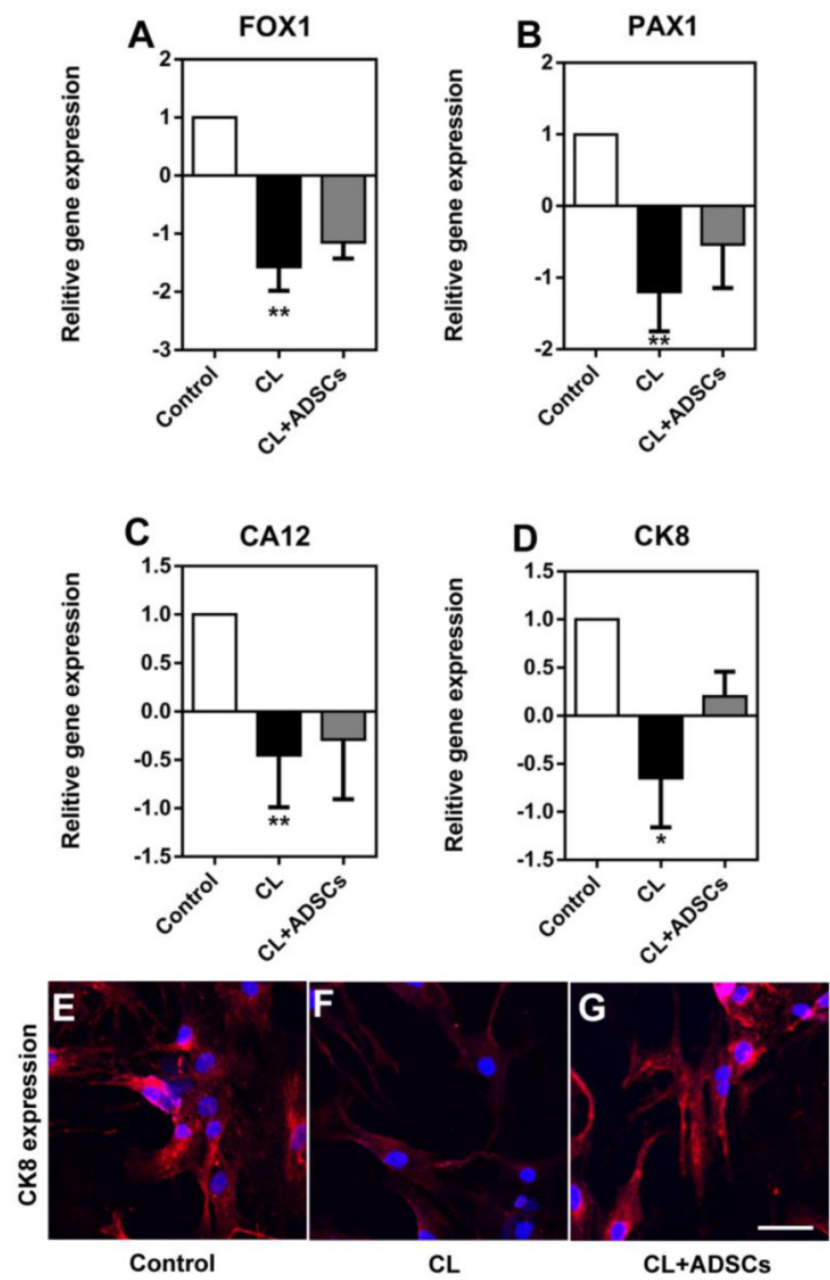

Figure 6: NP cell expression of FOXF1, PAX1, CA12 and CK8. Relative gene expression of FOXF1, PAX1, CA12 and CK8 as well as CK8 immunofluorescent staining was measured. (A-D) Reading each graph from left to right is the relative fold gene expression of NP cells treated without compressive load or ADSCs (white bar), $\mathrm{NP}$ cells treated with $\mathrm{CL}$ culture at $3.0 \mathrm{MPa}$ for $48 \mathrm{~h}$ (black bar) and NP cells treated with $C L+A D S C$ s at $3.0 M P a$ for $48 \mathrm{~h}$. The gene expression of FOXF1, PAX1, CA12 and CK8 was decreased by compressive load $\left(* * p<0.01,{ }^{*} p<0.05\right)$ and their expression was up-regulated by ADSCs insignificantly ( $p>0.05$ ). ( $E-G)$ CK8 expression was down-regulated by compressive load culture in protein level. The use of ADSCs led to an increase in the expression of CK8. Bar $=40 \mu \mathrm{m}$. Abbreviations: ADSCs (adipose-derived stromal cells), CL(compressive load), NP (nucleus pulposus), FOX1 (forkhead box F1), PAX1 (paired box 1), CA12 (carbonic anhydrase XII), CK8 (cytokeratin 8), qRT-PCR (quantitative real-time polymerase chain reaction).

and that intrinsic (mitochondrial) apoptotic pathway plays an important role in its mechanism. [10,31] Our results were consistent with these findings and importantly, we showed that the protective effect of ADSCs on NP cells might be mediated by the suppression of intrinsic (mitochondrial) apoptotic pathway and ADSCs might have less impact on Fas/FasL crosslink. Soluble factors secreted by ADSCs may contribute to this phenomenon. In particular, Caplan et al noted that stem cells secrete cytokines and growth factors that have both paracrine and autocrine activities. [19] Yamamoto et al found that cell-cell contact between MSCs and NP cells induced the secretion of growth factors. [16] Although the effect of these factors was not studied in load-induced apop- 
tosis, we consider that some group of them might play an important role in the protective impact of ADSCs. Further studies are needed to clarify this mechanism.

In IDD, the ECM of the disc undergoes structural, mechanical and molecular changes, which result in a loss of demarcation between the outer AF and the inner NP tissues. SOX9 is a transcription factor that is known to facilitate COL2A1 secretion and regarded as one of the most commonly used markers in the studies of stem cell differentiation to chondrocyte-like cells, especially NP cells. Collagen 2 is highly expressed in NP and its decrease is a classic pathological signature in IDD. In addition, collagen 6 and aggrecan express abundantly in NP. Studies noted that most ECM expression was decreased by abnormal compressive load environment both in vivo and in vitro. [32] In the present study, we showed that the expression of SOX9, COL2A1, ACAN, and COL6A2 was decreased by compressive load culture and the use of ADSCs strongly increased the expression of SOX9, COL2A1and ACAN, which indicated a protective effect on NP cell function. During the progress of IDD, alterations in collagen type and a decrease in proteoglycan content result in the loss of tissue integrity, decreased hydration, and thus lead to inability to withstand load. Our findings suggest that in ADSCs

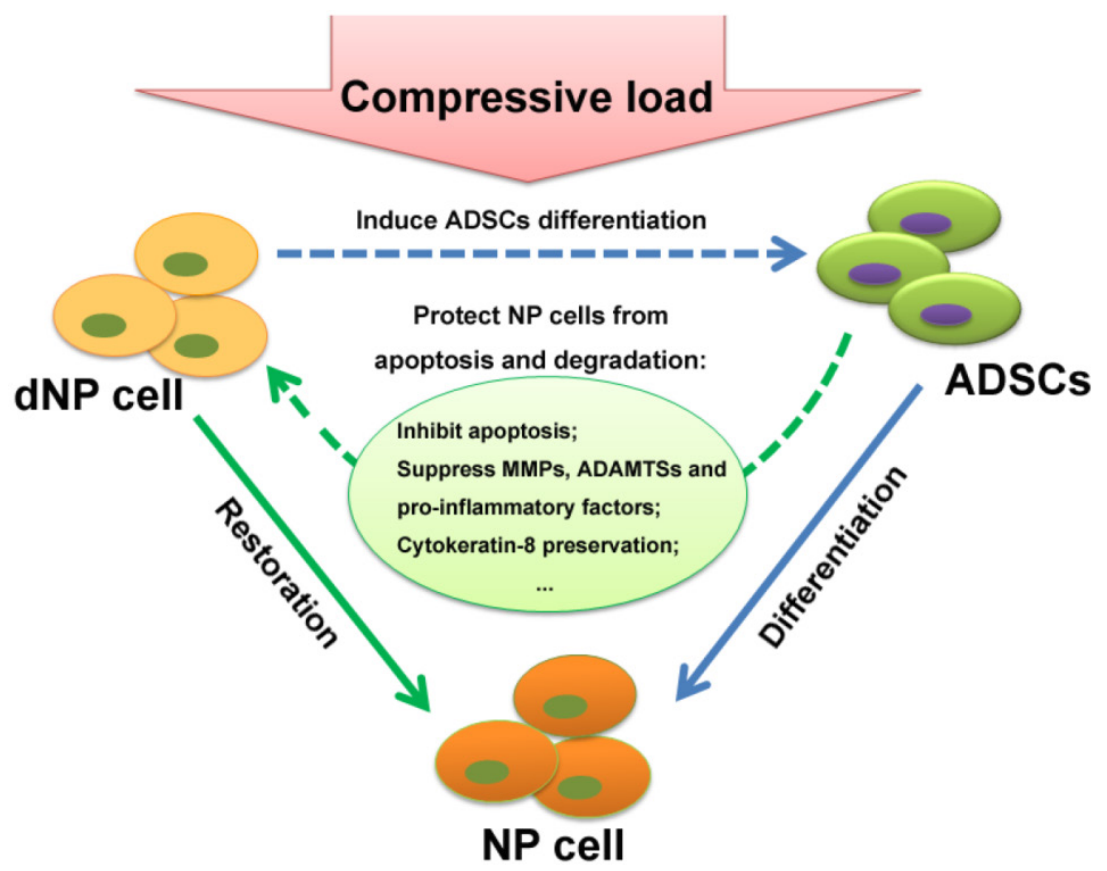

Figure 7: Schematic of interaction of NP cell and ADSCs in compressive load environment. In NP cell and ADSCs co-culture system, the NP cell can stimulate ADSCs differentiation to the NP cell phenotype, which is functional in synthesis of ECM, production of cytokines and maintenance of relevant enzymes' activities. On the other hand, as our results demonstrated in this study, the ADSCs could protect NP cells from apoptosis and degradation in compressive load environment via various molecular mechanisms: the inhibition of caspase 9 and caspase 3; the up-regulation of ECM, the suppression of MMPs and ADAMTSs and pro-inflammatory factors; the preservation of TIMPs and CK8. The reciprocal impact of the two types of cells found in this study made an essential understanding to expand our knowledge in ADSCs therapy for intervertebral disc regeneration. Abbreviations: ADSCs (adipose-derived stromal cells), ECM (extracellular matrix), NP (nucleus pulposus), MMPs (matrix metalloproteinases), ADAMTSs (A disintegrin and metalloproteinase with thrombospondin motifs), TIMPs (tissue inhibitor of matrix metalloproteinases), CK8 (cytokeratin 8). regeneration for IDD, the ADSCs could exert a regenerative effect not only by direct differentiation toward NP cells, but also benefit the existing NP cells to improve function in a detrimental environment.

In the cartilage, two classes of enzymes have been suggested to be involved in the breakdown of aggrecan. The first class is the matrix metalloproteinases (MMPs). [33] The second class is made of a group of proteases, ADAMTSs (a disintegrin and metalloproteinase with thrombospondin motifs). [34] In humans, there are currently 4 known tissue inhibitors of metalloproteinases (TIMPs), amongst which TIMP-1 and TIMP-2 are able to inhibit all MMPs. [35, 36] MMPs are a family of zinc-containing and zinc-dependent enzymes that have the ability to break down connective tissue by hydrolyzing components of the ECM. [37, 38] Studies have shown abnormal levels of MMPs in human degenerated discs. In particular, MMP-3 was highly suggested to be involved in IDD. [39, 40] MMP-13 is predominantly expressed by hypertrophic chondrocytes during endochondral ossification. [41] ADAMTSs are newly defined multidomain enzymes which are noted to be involved in IDD. $[42,43]$ We have previously shown that the gene expression of ADAMTS-1, 4, and 5 increased significantly in loaded NP cells. [28] In this study, we showed that these modulators were up-regulated by compressive load culture and ADSCs were able to decrease their expression. To further investigate the molecular mechanism, the activity of TIMPs, which are endogenous inhibitors of MMPs, was measured. TIMP-1 forms a complex with the catalytic domain of MMP-3 and TIMP-2 are able to inhibit all MMPs. Our results showed that TIMP-1 and TIMP-2 expression was increased by ADSCs; thereby, suggesting that they may play an important role in the decrease of MMPs.

Studies have shown that pro-inflammatory agents were up-regulated in degenerated NP tissue. [44-47] Importantly, it has been shown that mechanical stimulation, such as compressive load, could lead to the increase of pro-inflammatory agents, such as IL-1 $\beta$, IL-6, TGF- $\beta 1$ and TNF- $\alpha$. [48] Accordingly, the impact of ADSCs on the secretion of these agents is an important issue when used in disc regeneration, especially under abnormal compress load environment. In our study, the 
distinct capacity of ADSCs on pro-inflammatory factors suppression suggested that ADSCs treatment might inhibit pro-inflammatory degrading mediators in disc regeneration.

Although it remains largely unknown in the exact phenotypes of human NP cells, some studies have attempted to identify NP cell markers. $[49,50]$ In this field, Minogue et al [51] showed FOXF1, PAX1 and CA12 positively expressed in NP cells by microarray analysis. Our previous studies also indicated that CK8 expression decreased with progression of IDD pathology and were closely linked with compressive load culture. [29, 52] In the current study, though ADSCs showed no significant influence on FOXF1, PAX1, CA12 and CK8 gene expression, the decrease protein expression of CK8 was prevented by ADSCs in compressive load culture.

\section{Conclusions}

Our study is the first in vitro study assessing the impact of ADSCs on NP cells in an un-physiological mechanical stimulation culture environment. Our study demonstrated that ADSCs are protective against NP apoptosis via suppression of activated caspase-9 and -3. Moreover, ADSCs showed a beneficial effect on NP cells by increasing functional ECM and TIMPs expression while inhibiting MMPs, ADAMTSs and pro-inflammatory agents expression. Although ADSCs showed no effect on most NP markers expression, they inhibited the decrease of CK8.

The results of the present study provide much needed evidence that ADSCs provide crucial protective effects that mediate apoptosis and degradation of NP cells induced by compressive load. Further studies are needed to classify the molecular mechanisms in molecular signals. Consequently, the reciprocal impact of the two types of cells found in this study might make an essential understanding to expand our knowledge in ADSCs-based therapies for intervertebral disc regeneration.

\section{Abbreviations}

ACAN: aggrecan; ADAMTSs: a disintegrin and metalloproteinase with thrombospondin motifs; ADSCs: adipose-derived stromal cells; AF: annulus fibrosus; CA12: carbonic anhydrase XII; CK8: cytokeratin 8; COL1A2: type II collagen a 2 chain; COL6A2: type VI collagen a 2 chain; ECM: extracellular matrix; FOX1: forkhead box F1; IDD: intervertebral disc degeneration; IL-1 $\beta$ : interleukin-1 $\beta$; IL-6: interleukin-6; MMPs: matrix metalloproteinases; NP: nucleus pulposus; PAX1: paired box 1; SEM: scanning electron microscopy; SOX9: sry-related HMG box 9; TGF- $\beta 1$ : transforming growth factor $\beta 1$; TIMPs: tissue inhibitors of metalloproteinases; TNF-a: tumor necrosis factor $a$.

\section{Supplementary Material}

Tables S1 - S2.

http://www.ijbs.com/v11p0133s1.pdf

\section{Acknowledgements}

This work was supported by the Chinese National Natural Science Foundation Grants (No. 81171747).

\section{Author Contributions}

ZS: Conception and design, Collection and/or assembly of data, Data analysis and interpretation, Manuscript writing. BL: Conception and design, Collection and/or assembly of data, Data analysis and interpretation, Manuscript writing. ZHL: Collection and/or assembly of data, Data analysis and interpretation, Manuscript writing. DS: Data analysis and interpretation, Manuscript writing, Critical Revision. ZL, BG and LH: Collection and/or assembly of data, Data analysis and interpretation, ZJL: Conception and design, Data analysis and interpretation, Manuscript writing. All authors read and approved the final manuscript.

\section{Competing interest}

All authors state that there is no conflict of interests.

\section{References}

1. Andersson GB. Epidemiological features of chronic low-back pain. Lancet. 1999; 354: 581-5. doi:10.1016/S0140-6736(99)01312-4.

2. Vos T, Flaxman AD, Naghavi M, Lozano R, Michaud C, Ezzati M, et al. Years lived with disability (YLDs) for 1160 sequelae of 289 diseases and injuries 1990-2010: a systematic analysis for the Global Burden of Disease Study 2010. Lancet. 2012; 380: 2163-96. doi:10.1016/S0140-6736(12)61729-2.

3. Rubin DI. Epidemiology and risk factors for spine pain. Neurologic clinics. 2007; 25: 353-71. doi:10.1016/j.ncl.2007.01.004.

4. Fraser RD, Osti OL, Vernon-Roberts B. Intervertebral disc degeneration. European spine journal : official publication of the European Spine Society, the European Spinal Deformity Society, and the European Section of the Cervical Spine Research Society. 1993; 1: 205-13.

5. Peng B, Wu W, Hou S, Li P, Zhang C, Yang Y. The pathogenesis of discogenic low back pain. The Journal of bone and joint surgery British volume. 2005; 87: 62-7.

6. Samartzis D, Karppinen J, Cheung JP, Lotz J. Disk Degeneration and Low Back Pain: Are They Fat-Related Conditions? Global spine journal. 2013; 3: 133-44. doi:10.1055/s-0033-1350054.

7. Sun Z, Zhang M, Zhao XH, Liu ZH, Gao Y, Samartzis D, et al. Immune cascades in human intervertebral disc: the pros and cons. International journal of clinical and experimental pathology. 2013; 6: 1009-14.

8. Hutton WC, Toribatake Y, Elmer WA, Ganey TM, Tomita K, Whitesides TE. The effect of compressive force applied to the intervertebral disc in vivo. A study of proteoglycans and collagen. Spine. 1998; 23: 2524-37.

9. Lotz JC, Chin JR. Intervertebral disc cell death is dependent on the magnitude and duration of spinal loading. Spine. 2000; 25: 1477-83.

10. Kuo YJ, Wu LC, Sun JS, Chen MH, Sun MG, Tsuang YH. Mechanical stress-induced apoptosis of nucleus pulposus cells: an in vitro and in vivo rat model. Journal of orthopaedic science : official journal of the Japanese Orthopaedic Association. 2014; 19: 313-22. doi:10.1007/s00776-013-0510-2.

11. Yang F, Leung VY, Luk KD, Chan D, Cheung KM. Mesenchymal stem cells arrest intervertebral disc degeneration through chondrocytic differentiation and stimulation of endogenous cells. Molecular therapy : the journal of the American Society of Gene Therapy. 2009; 17: 1959-66. doi:10.1038/mt.2009.146. 
12. Orozco $\mathrm{L}$, Soler $\mathrm{R}$, Morera $\mathrm{C}$, Alberca $\mathrm{M}$, Sanchez A, Garcia-Sancho J. Intervertebral disc repair by autologous mesenchymal bone marrow cells: a $\begin{array}{lllll}\text { pilot } & \text { study. } & \text { Transplantation. } & \text { 2011; } & \text { 92: }\end{array}$ doi:10.1097/TP.0b013e3182298a15.

13. Yoshikawa T, Ueda Y, Miyazaki K, Koizumi M, Takakura Y. Disc regeneration therapy using marrow mesenchymal cell transplantation: a report of two case studies. Spine. 2010; 35: E475-80. doi:10.1097/BRS.0b013e3181cd2cf4.

14. Tapp H, Hanley EN, Jr., Patt JC, Gruber HE. Adipose-derived stem cells: characterization and current application in orthopaedic tissue repair. Experimental biology and medicine. 2009; 234: 1-9. doi:10.3181/0805/MR-170.

15. Vadala G, Studer RK, Sowa G, Spiezia F, Iucu C, Denaro V, et al. Coculture of bone marrow mesenchymal stem cells and nucleus pulposus cells modulate gene expression profile without cell fusion. Spine. 2008; 33: 870-6. doi:10.1097/BRS.0b013e31816b4619.

16. Yamamoto Y, Mochida J, Sakai D, Nakai T, Nishimura K, Kawada H, et al. Upregulation of the viability of nucleus pulposus cells by bone marrow-derived stromal cells: significance of direct cell-to-cell contact in coculture system. Spine. 2004; 29: 1508-14.

17. Strassburg S, Richardson SM, Freemont AJ, Hoyland JA. Co-culture induces mesenchymal stem cell differentiation and modulation of the degenerate human nucleus pulposus cell phenotype. Regenerative medicine. 2010; 5: 701-11. doi:10.2217/rme.10.59.

18. Miyamoto T, Muneta T, Tabuchi T, Matsumoto K, Saito H, Tsuji K, et al. Intradiscal transplantation of synovial mesenchymal stem cells prevents intervertebral disc degeneration through suppression of matrix metalloproteinase-related genes in nucleus pulposus cells in rabbits. Arthritis research \& therapy. 2010; 12: R206. doi:10.1186/ar3182.

19. Caplan AI, Dennis JE. Mesenchymal stem cells as trophic mediators. Journal of cellular biochemistry. 2006; 98: 1076-84. doi:10.1002/jcb.20886.

20. Sun Z, Liu ZH, Zhao XH, Sun L, Chen YF, Zhang WL, et al. Impact of direct cell co-cultures on human adipose-derived stromal cells and nucleus pulposus cells. J Orthop Res. 2013; 31: 1804-13. doi:10.1002/jor.22439.

21. Handa T, Ishihara H, Ohshima H, Osada R, Tsuji H, Obata K. Effects of hydrostatic pressure on matrix synthesis and matrix metalloproteinase production in the human lumbar intervertebral disc. Spine. 1997; 22: 1085-91.

22. Liu GZ, Ishihara H, Osada R, Kimura T, Tsuji H. Nitric oxide mediates the change of proteoglycan synthesis in the human lumbar intervertebral disc in response to hydrostatic pressure. Spine. 2001; 26: 134-41.

23. Chan SC, Ferguson SJ, Gantenbein-Ritter B. The effects of dynamic loading on the intervertebral disc. European Spine Journal. 2011; 20: 1796-812. doi:10.1007/s00586-011-1827-1.

24. Chun HJ, Kim YS, Kim BK, Kim EH, Kim JH, Do BR, et al. Transplantation of human adipose-derived stem cells in a rabbit model of traumatic degeneration of lumbar discs. World neurosurgery. 2012; 78: 364-71. doi:10.1016/j.wneu.2011.12.084

25. Yang X, Li X. Nucleus pulposus tissue engineering: a brief review. European spine journal : official publication of the European Spine Society, the European Spinal Deformity Society, and the European Section of the Cervical Spine Research Society. 2009; 18: 1564-72. doi:10.1007/s00586-009-1092-8.

26. Yi Z, Guanjun T, Lin C, Zifeng P. Effects of Transplantation of hTIMP1-Expressing Bone Marrow Mesenchymal Stem Cells on the Extracellular Matrix of Degenerative Intervertebral Discs in an in vivo Rabbit Model. Spine. 2014. doi:10.1097/BRS.0000000000000316

27. Leung VY, Aladin DM, Lv F, Tam V, Sun Y, Lau RY, et al. Mesenchymal stem cells reduce intervertebral disc fibrosis and facilitate repair. Stem cells. 2014. doi:10.1002/stem.1717.

28. Huang $M$, Wang $H Q$, Zhang $Q$, Yan XD, Hao M, Luo ZJ. Alterations of ADAMTSs and TIMP-3 in human nucleus pulposus cells subjected to compressive load: Implications in the pathogenesis of human intervertebral disc degeneration. J Orthop Res. 2012; 30: 267-73. doi:10.1002/jor.21507.

29. Sun Z, Guo YS, Yan SJ, Wan ZY, Gao B, Wang L, et al. CK8 phosphorylation induced by compressive loads underlies the downregulation of CK8 in human disc degeneration by activating protein kinase C. Laboratory investigation; a journal of technical methods and pathology. 2013; 93: 1323-30. doi:10.1038/labinvest.2013.122.

30. Kermani HR, Hoboubati H, Esmaeili-Mahani S, Asadi-Shekaari M. Induction of intervertebral disc cell apoptosis and degeneration by chronic unpredictable stress. Journal of neurosurgery Spine. 2014; 20: 578-84. doi:10.3171/2014.1.SPINE13466.

31. Yamada K, Sudo H, Iwasaki K, Sasaki N, Higashi H, Kameda Y, et al. Caspase 3 silencing inhibits biomechanical overload-induced intervertebral disk degeneration. The American journal of pathology. 2014; 184: 753-64. doi:10.1016/j.ajpath.2013.11.010.

32. Korecki CL, MacLean JJ, Iatridis JC. Dynamic compression effects on intervertebral disc mechanics and biology. Spine. 2008; 33: 1403-9. doi:10.1097/BRS.0b013e318175cae7.

33. Saliken DJ, Mulet-Sierra A, Jomha NM, Adesida AB. Decreased hypertrophic differentiation accompanies enhanced matrix formation in co-cultures of outer meniscus cells with bone marrow mesenchymal stromal cells. Arthritis research \& therapy. 2012; 14: R153. doi:10.1186/ar3889.

34. Pockert AJ, Richardson SM, Le Maitre CL, Lyon M, Deakin JA, Buttle DJ, et al. Modified expression of the ADAMTS enzymes and tissue inhibitor of metalloproteinases 3 during human intervertebral disc degeneration. Arthritis and rheumatism. 2009; 60: 482-91. doi:10.1002/art.24291.
35. Assirelli E, Pulsatelli L, Dolzani P, Platano D, Olivotto E, Filardo G, et al. Human Osteoarthritic Cartilage Shows Reduced In Vivo Expression of IL-4, a Chondroprotective Cytokine that Differentially Modulates IL-1beta-Stimulated Production of Chemokines and Matrix-Degrading Enzymes In Vitro. PloS one. 2014; 9: e96925. doi:10.1371/journal.pone.0096925.

36. Wu TY, Zhang TH, Qu LM, Feng JP, Tian LL, Zhang BH, et al. MiR-19a is correlated with prognosis and apoptosis of laryngeal squamous cell carcinoma by regulating TIMP-2 expression. International journal of clinical and experimental pathology. 2014; 7: 56-63.

37. Visse R, Nagase H. Matrix metalloproteinases and tissue inhibitors of metalloproteinases: structure, function, and biochemistry. Circulation research. 2003; 92: 827-39. doi:10.1161/01.RES.0000070112.80711.3D.

38. Bayo J, Fiore E, Aquino JB, Malvicini M, Rizzo M, Peixoto E, et al. Increased Migration of Human Mesenchymal Stromal Cells by Autocrine Motility Factor (AMF) Resulted in Enhanced Recruitment towards Hepatocellular Carcinoma. PloS one. 2014; 9: e95171. doi:10.1371/journal.pone.0095171.

39. Nemoto $O$, Yamagishi $M$, Yamada $H$, Kikuchi $T$, Takaishi H. Matrix metalloproteinase-3 production by human degenerated intervertebral disc. Journal of spinal disorders. 1997; 10: 493-8.

40. Furtwangler T, Chan SC, Bahrenberg G, Richards PJ, Gantenbein-Ritter B. Assessment of the matrix degenerative effects of MMP-3, ADAMTS-4, and HTRA1, injected into a bovine intervertebral disc organ culture model. Spine. 2013; 38: E1377-87. doi:10.1097/BRS.0b013e31829ffde8.

41. Marriott A, Ayad S, Grant ME. The synthesis of type X collagen by bovine and human growth-plate chondrocytes. Journal of cell science. 1991; 99 ( Pt 3): $641-9$

42. Malfait AM, Liu RQ, Ijiri K, Komiya S, Tortorella MD. Inhibition of ADAM-TS4 and ADAM-TS5 prevents aggrecan degradation in osteoarthritic cartilage. The Journal of biological chemistry. 2002; 277: 22201-8. doi:10.1074/jbc.M200431200.

43. Vo NV, Hartman RA, Yurube T, Jacobs LJ, Sowa GA, Kang JD. Expression and regulation of metalloproteinases and their inhibitors in intervertebral disc aging and degeneration. The spine journal : official journal of the North American Spine Society. 2013; 13: 331-41. doi:10.1016/j.spinee.2012.02.027.

44. Takahashi H, Suguro T, Okazima Y, Motegi M, Okada Y, Kakiuchi T. Inflammatory cytokines in the herniated disc of the lumbar spine. Spine. 1996; 21: 218-24.

45. Bachmeier BE, Nerlich AG, Weiler C, Paesold G, Jochum M, Boos N. Analysis of tissue distribution of TNF-alpha, TNF-alpha-receptors, and the activating TNF-alpha-converting enzyme suggests activation of the TNF-alpha system in the aging intervertebral disc. Annals of the New York Academy of Sciences. 2007; 1096: 44-54. doi:10.1196/annals.1397.069.

46. Hoyland JA, Le Maitre C, Freemont AJ. Investigation of the role of IL-1 and TNF in matrix degradation in the intervertebral disc. Rheumatology. 2008; 47: 809-14. doi:10.1093/rheumatology/ken056.

47. Wuertz K, Vo N, Kletsas D, Boos N. Inflammatory and catabolic signalling in intervertebral discs: the roles of NF-kappaB and MAP kinases. European cells \& materials. 2012; 23: 103-19; discussion 19-20.

48. Kang JD, Stefanovic-Racic M, McIntyre LA, Georgescu HI, Evans CH. Toward a biochemical understanding of human intervertebral disc degeneration and herniation. Contributions of nitric oxide, interleukins, prostaglandin E2, and matrix metalloproteinases. Spine. 1997; 22: 1065-73.

49. Lee CR, Sakai D, Nakai T, Toyama K, Mochida J, Alini M, et al. A phenotypic comparison of intervertebral disc and articular cartilage cells in the rat. European spine journal : official publication of the European Spine Society, the European Spinal Deformity Society, and the European Section of the Cervical Spine Research Society. 2007; 16: 2174-85. doi:10.1007/s00586-007-0475-y.

50. Gilson A, Dreger M, Urban JP. Differential expression level of cytokeratin 8 in cells of the bovine nucleus pulposus complicates the search for specific intervertebral disc cell markers. Arthritis research \& therapy. 2010; 12: R24. doi:10.1186/ar2931.

51. Minogue BM, Richardson SM, Zeef LA, Freemont AJ, Hoyland JA. Characterization of the human nucleus pulposus cell phenotype and evaluation of novel marker gene expression to define adult stem cell differentiation. Arthritis and rheumatism. 2010; 62: 3695-705. doi:10.1002/art.27710.

52. Sun Z, Wang HQ, Liu ZH, Chang L, Chen YF, Zhang YZ, et al. Down-regulated CK8 expression in human intervertebral disc degeneration. International journal of medical sciences. 2013; 10: 948-56. doi:10.7150/ijms.5642. 